\title{
Recognition and Incentive: The Value of an Institutional Strategy for Faculty Awards
}

\author{
Bob Wilhelm, Ph.D., Vice Chancellor of Research and Economic \\ Development, University of Nebraska-Lincoln
}

Dawn O. Braithwaite, Ph.D., Willa Cather Professor and Chair, Department of Communication Studies, University of Nebraska-Lincoln

\section{Liz Lange, National Recognition and Awards Coordinator, University of Nebraska-Lincoln}

$\mathrm{F}$ ramed within current developments and future expectations for open-access data and scholarship in research universities, considerations of the practice and meanings of interdisciplinary and interinstitutional research will continue to expand. Inherent in considerations of open-access data and scholarship are implications for assessment of scholars and scholarship and, in particular, the role of open-access on evaluation of researchers in the university environment, and in particular on tenure and promotion. This raises broader issues of evaluation and recognizing achievement in the university, in the context of changes in how scholarship is pursued and evaluated.

In 2000, the University of Nebraska-Lincoln's (UNL) convened a Future Nebraska Task Force to imagine next steps for the nature, scope, and quality of the institution's research enterprise with consideration of ways to incentivize and recognize excellence. The committee's corresponding report, $A$ 2020 Vision: The Future of Research and Graduate Education at the University of Nebraska-Lincoln, outlined the characteristics of a "vigorous academic community." It read, in part:

"A vigorous academic community finds ways to value, celebrate, and make visible in the everyday life of our institution its outstanding academic achievers... it has often been said that an institution becomes what it celebrates and honors and we cannot become an institution of high academic success if we do not honor those individuals and teams among us who achieve success in their scholarly endeavors... When we do showcase our best faculty, everyone feels better, not worse: it's exciting, thrilling, selfsatisfying to know that people this good are our colleagues and it encourages a culture in which people take pride and add to their own stock of self-esteem via the institution's achievements, stature and reputation. And when this is done on a regular basis, and in all areas of scholarly endeavor, it creates a collective experience of institutional pride that breeds even more success." 
It is in the timeless spirit of this almost 20-year-old report that UNL began to focus more intentionally on promoting awards activity in 2011. Indeed, focused pursuit of national awards and honors for faculty is a hallmark of a culture that incentivizes, recognizes, and celebrates outstanding achievement while at the same time producing collateral advantage through enhancing individual faculty careers, building departmental profiles, and advancing the reputation of the university as a whole.

\section{Rationale}

A recent Science article (May 2017) lays out the important role of awards in a faculty member's career. Benefits of applying for awards include increased visibility and improved networking and collaboration opportunities as well as an opportunity to practice the skill of promoting oneself. Further, taking the time to compile the nomination package and connect with mentors provides a structured opportunity to reflect on and assess professional progress and any corresponding gaps, especially in early career stages. Perhaps from a broader perspective, awards can also serve as an important institutional retention tool. In addition, awards are consistently and increasingly an important indicator in and component of scholarly production and institutional rankings. All of these benefits in mind, it is also important to note the overall positive nature of awards-simply put, awards make people feel good and offer an opportunity to celebrate a career's hard work and excellence, an outcome with value and incentive in and of itself.

Further, a relatively recent line of incentive economics research (e.g. Frey \& KU MASC 2018 Research Retreat
Neckerman, 2009; Chan, et al., 2014) explores the connection between awards and faculty performance as well as the utility of awards as a means of motivation for researchers, in particular in comparison to monetary recognition. Among other findings, these papers note that awards are a viable and effective instrument in encouraging and advancing research performance and that, following receipt of awards, research productivity and citations increase in a statistically significant way. While researchers note the complications and limitations of any approach attempting to isolate the impact of external incentives on performance and motivation, with these conclusions in mind, it may be helpful for institutions to consider this research when contemplating various award, recognition, and incentive strategies.

At Nebraska, the focus on awards became an institutional priority in 2011. In his State of the University address that year, then-Chancellor Harvey Perlman emphasized the need for increasing our academic stature and challenged the campus with ambitious goals for increasing growth in research and economic development. Specifically related to awards, the goal was to double the number of faculty receiving prestigious national awards and memberships in honorary societies.

\section{Role and services}

To implement and operationalize this work, UNL leadership collaborated on the structure and centralized support by establishing a full-time position dedicated to promoting, coordinating, and tracking awards. Three senior leaders - the Senior Vice Chancellor for Academic Affairs (today the Executive 40 
Vice Chancellor and Chief Academic Officer), the Vice Chancellor for Research and Economic Development, and the Vice Chancellor for the Institute of Agriculture and Natural Resourcesshared the cost of establishing the position, making professional services and expertise available across the campus. The National Recognition and Awards Coordinator is administratively housed in the Office of Research and Economic Development (ORED) as the role is most closely aligned with its research development activities.

A variety of barriers inhibit faculty from pursuing awards, such as faculty humility or concerns about competition, lack of knowledge about the existence of awards or how to apply, learning to navigate the process and needed patience when not successful the first time, and legitimate time concerns and restraints for both faculty and administration. The availability and expertise of the National Recognition and Awards Coordinator at Nebraska relieves some of the more practical concerns while offering a resource for managing logistics of application and university-level recognition.

Operationally, the Coordinator takes a broad approach to the national awards universe and offers professional services across campus, including:

- Identifying opportunities that align with faculty expertise

- Facilitating nomination process nuts and bolts, such as:

- Review of guidelines and eligibility, including analysis of past winners

- Communicating with the award sponsor with any questions
- Coordinating with nominators, both internal and external

- Editing and drafting nomination materials to tell a compelling story of career impact

- CV coaching, tailoring, and editing

- Monitoring progress toward deadlines

- Tracking institutional submissions and receipt of awards

- Reporting results to university leadership on a quarterly basis

In addition to supporting nominations, an important component of the Coordinator's work involves an ongoing effort to shift the institutional culture around the value of this activity. In part, this involves consistently communicating the value of awards to faculty and administrators (see a description of communications activities below) and recognizing faculty and their administrators when the process has a successful outcome.

\section{Strategies and communication}

The National Recognition and Awards Coordinator position deploys multiple strategies to catalyze this type of activity at Nebraska, for example:

- Conducting outreach across the university through presentations and individual meetings.

- Analyzing past award data and guiding focused planning

- Targeting certain departments and faculty members for nomination

- Sharing success and celebrating award winners through strategic communications 
- Working with university leadership to develop consistent messaging and outreach

It has become increasingly important to partner with institution-wide communications offices, especially the centralized University Communications as well as unit and college offices, to ensure that awards are widely publicized. This is a critical component of the awards strategy; if the awards are won in isolation, without any publication or recognition, it limits the overall incentive and resulting cultural impact.

We have also developed a strategic set of collateral materials, including a comprehensive awards web site with a listing of award winners, a promotional video, and professionally designed flyers. The web site, launched in August 2017, has proven a useful tool for promotion, with positive response and participation from faculty. The awards listing is regularly updated through various resources, including Academic Analytics data and direct communication with individual faculty and departments.

The campus video, featuring faculty and administrators speaking to their personal experience with awards, has also proven an effective approach in promoting awards and engaging institutional leadership to shape and share the message. Along with perspectives from several award winners and a Department Chair, the video includes UNL's current Chancellor, Dr. Ronnie Green, who inspires and incentivizes action by speaking to both the personal and institutional value of awards. The video was first shown at the annual ORED Research Fair Awards Breakfast in November 2017 and has been used on the web site and in smaller meeting settings since that time. It was also part of a campus-based online Nebraska Today newsletter feature article outlining institutional awards success in fall 2017, which generated a good deal of positive attention for the National Recognition and Awards Coordinator and the awards strategy.

A final strategy that has paid unexpected dividends is a personal letter of congratulations from Chancellor Green to individual award winners, which includes more specific information than just the award title, for example, text from the announcement and specific testament to the award winner. The letters are sent on a bi-monthly basis, with copies to Deans and Chairs, and the response has been overwhelmingly positive. The Chancellor regularly receives replies of gratitude, demonstrating the impact of this personal form of recognition. Chairs have also noted how meaningful the letters are to all faculty, especially to early career faculty. Most recently, a letter was quoted in a communications piece announcing a Fulbright Scholar award, extending the Chancellor's message to a wider audience. This relatively simple recognition sends a signal that the highest levels of leadership are paying attention to and care about individual awards and careers, which further incentivizes award activity.

\section{Results}

The awards story at Nebraska demonstrates the kind of results that are possible when an institution invests focused time, resources, and energy toward pursuit of this goal. Since focusing on national recognition and 
awards, UNL has exceeded the original goal set in 2011, having more than tripled the number of awards earned by faculty as recognized by the National Research Council (NRC). (The NRCS maintains a list of over 1,300 awards recognized as "highly prestigious" or "prestigious.").

The data outlined here focus on NRC awards as a benchmark from which to measure progress. That said, award efforts include all national awards important to individual careers and within disciplines. For example, the list of awards maintained by the NRC does not focus as heavily on teaching, service, or

\section{Model departments}

The culture and leadership of individual departments plays a significant role in awards success. Many times, Chairs and Heads drive awards activity for a department, as they are most familiar with faculty strengths and career trajectory. Several departments at Nebraska take a strategic approach to award nominations, through either an established awards committee or a committed Chair.

For example, the Department of Communication Studies in the College of Arts and Sciences has a long history of

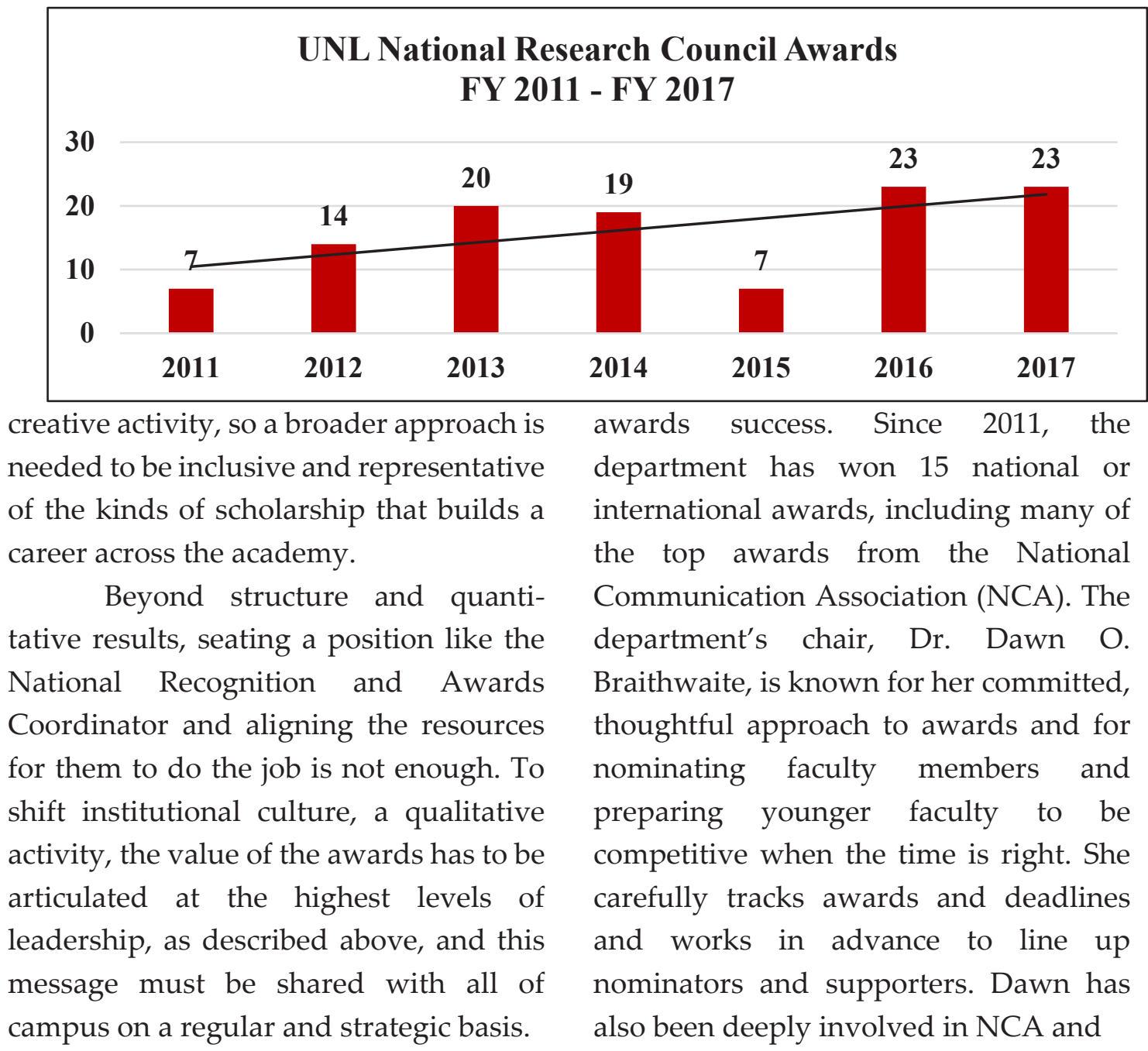


other associations, having served as President and in many other capacities and, at the same time, building a professional network that we know is so critical to awards success. She has also worked with the national association to research and expand their list of awards for which members can apply. In fact, Dawn is so well known for her work with awards that the Central States Communication Association recently named an award after her. The inaugural Dawn O. Braithwaite Award for Qualitative Research was presented at the April 2018 meeting. This demonstrates the impact of awards leadership on a department and discipline.

Another successful department, Biological Systems Engineering, has a track record of successfully nominating its faculty for awards, with a recent string of awards from its professional society the American Society of Agricultural and Biological Engineers (ASABE). Since 2012, the Department has won 13 of ASABE's major awards and, since 2014, four faculty have won all of the most prestigious early career awards (across teaching, research, and service categories). The National Recognition and Awards Coordinator worked with ORED Communications to highlight these achievements through an article, "Blueprint for Success: Department's Culture Creates Model for National Awards Success." Sent as a feature in ORED's monthly newsletter, this article held up an exemplar department and described for all of campus how its approach to and strategies for awards have been successful in building its profile.

\section{Next steps and conclusion}

Though Nebraska has made much progress within the awards arena, there is ongoing room for improvement. For example, there are several high-performing departments, as measured by other metrics, which do not yet focus on awards. Moreover, there is a need to target the humanities, social sciences, and performing arts, both as a welcoming entry point into ORED and as a strategy to diversify the type of awards being pursued.

To further institutionalize this activity and to drive success through individual departments, we are currently developing a structure and program to promote awards more directly to departments and Chairs through a "department awards committee startup package." This package will offer best practices around awards committee make up and function as well as strategic support offerings to alleviate some of the pressures for departmental executives. In part, this targeted outreach will focus on humanities and social sciences to meet other needs for growth. There is also an ongoing need to diversify nominees and help faculty think about and build their external networks as an important component of being award ready.

There is always more work to be done, but the ongoing potential of awards at Nebraska is clear: a dedicated position like the National Recognition and Awards Coordinator can serve as an enzyme-catalyzing activity across campus to incentivize and increase faculty awards and recognition and making a difference to advance the university. 


\section{References}

S.A. Holgate. "The benefits of awards-even if you don't win.” Science. (2017).

doi:10.1126/science.caredit.a1700044

B.S. Frey and S. Neckermann. (2009). Academics appreciate awards: A new aspect of incentives in research. CESifo Working Paper No. 2531.

H.F. Chan, B.S. Frey, J. Gallus, and B. Torgler. (2014). Academic honors and performance. Labour Economics, 31, 188-204.

\section{Related reading list}

T.M. DiLorenzo and P.P. Heppner. (1994). The Role of an Academic Department in Promoting Faculty Development: Recognizing Diversity and Leading to Excellence, Journal of Counseling and Development, 72 (5), 485-91.

M.D. Miller. Forget mentors - what we really need are fans. (2018, 22 February).

Chronicle of Higher Education. Retrieved from http://chronicle.com 